\title{
Analysis of the Fashion Design in Network
}

\author{
Siyun Chen \\ Guangdong University of Science \& Technology, Dongguan 523083, China
}

Keywords: network age, costume, design, concept.

\begin{abstract}
Clothing is an important standard of living,because it is closely related to people's daily life. In people's lives, clothing is always associated with fashion and style together. Especially the fashion design concept of the update express the trend of each era and spiritual style. Therefore, the study of the concept of network era clothing design is very important. For an era of the overall trend of fashion design, the perfect combination of art and science and technology are an area we must pay attention to.
\end{abstract}

\section{Introduction}

The development of science and technology has also brought about the innovation of art and the increasingly accumulated knowledge has accelerated the progress of science and technology. The Internet age has changed the people's ideas and the concept of time and space. People's life production methods, life concepts, design ideas and the traditional way form a sharp contrast and present a new concept. Therefore, for the current struggle in the field of fashion design, art and design areas of competition are becoming increasingly fierce. Learning to analyze the concept of the Internet era and the inherent organic connection between the designs, fashion designers are grasping the pulse of the times and control the design of the real power of the original lies.

\section{Interpretation of the design of clothing}

The concept of clothing design is: "If clothing is as the object, we can consider its various functional, select the material, the use of certain techniques to complete a clothing body, so that the idea of materialized creative behavior." (Cited from Lee when the "clothing "This is a state of design.)This state is the body after the dress of a state. Because of its functional can meet people's physiological needs and psychological needs, so that this state can achieve perfection. Therefore, to meet the physiological needs of the human body material relies on scientific means to obtain, which requires designers to have a certain degree of scientific literacy, so that his design results have a certain scientific nature. At the same time, in order to meet people's psychological needs, but also need the designer with a certain artistic accomplishment, he designed works to meet people's aesthetic taste, reflecting the rich spirit and cultural connotations.

\section{Cultural Trend of Thought and Overall Development Trend in Network}

\subsection{The cultural trend of the Internet age}

In the process of network industry development, the knowledge industry and commodity industry are the result of all-round progress of human culture and art, economic life, philosophical thought and industrial design. This is also the economic sublimation, design transformation and the effect of materialization. Knowledge industry is the cultural spirit, design, creative materialization. This is the concept of goods, economy and industry. It also can be said to culture, knowledge, talent, network, technology, computer industry, innovation and other basic elements of life. Therefore, the overall characteristics of the Internet age, the structure from different degrees can performe the era of the development track. Commodities must be highly artistic, in line with the needs of the public. To meet the needs of the development of the times is in a sense is a return. Clothing design concept is the return of creativity, knowledge, economy, science and technology, art of organic integration.

\subsection{The overall trend of the Internet era}




\subsubsection{Rapid transformation of scientific and technological achievements}

In the process of scientific and technological achievements, it is particularly important to focus on innovation and strengthen innovation. Innovation is the soul of a nation's progress and is also an inexhaustible motive force for the development of a country or cultivate creativity. Japan CI design master Mr. West yuan thinks that: networked society should have the international beauty, personality, creativity, the enterprise. The most important thing is not a simple expression of the United States, but the economy and the era of synchronization.

\subsubsection{Cultural knowledge and commodity links}

Cultural knowledge and commodity are linked to the link between goods and works of art. Knowledge and high technology are combined to make the traditional knowledge of goods, which makes the cultural consumption more abundant, novel, beautiful, and presents a diversified pattern, such as clothing design.

\subsubsection{Knowledge of materialization}

In this area, the most universal is the knowledge of the property and its representative of the materialization of the formation of the concept of industrial culture, such as the use of traditional culture to the clothing design are showing the development trend of knowledge property.

\subsubsection{Cultural knowledge activities are becoming more frequent}

Cultural knowledge Economic activities, cultural shopping, cultural services and cultural knowledge tourism can constitute another era of the network era. Today, the traditional sense of elegance, noble have been popular and civilians, and in some areas these have been materialized as cultural and artistic works. The property is no longer a single, non-human, but full of emotion and colorful. Man and art can no longer be separated. The center of the subject is man, then man can provide the beauty pattern and service for the public.

Here, with Table 1 to express the network era under the overall trend of fashion design, which can be used to reflect the different trends in the development of fashion design in people's popularity.

Table 1: The overall trend of fashion design under the Internet age

\begin{tabular}{|c|c|c|}
\hline $\begin{array}{l}\text { Overall development trend } \\
\text { type }\end{array}$ & main content & On behalf of the design \\
\hline $\begin{array}{c}\text { Rapid transformation of } \\
\text { scientific and technological } \\
\text { achievements }\end{array}$ & Focus on innovation and innovation & $\begin{array}{l}\text { Clothing } \\
\text { internationalization }\end{array}$ \\
\hline $\begin{array}{l}\text { Cultural knowledge and } \\
\text { commodity linkages }\end{array}$ & $\begin{array}{l}\text { The traditional knowledge of goods, } \\
\text { cultural consumption more abundant }\end{array}$ & $\begin{array}{l}\text { Clothing pattern } \\
\text { diversification }\end{array}$ \\
\hline $\begin{array}{l}\text { Knowledge of } \\
\text { materialization }\end{array}$ & $\begin{array}{l}\text { The formation of industrial culture } \\
\text { conceptualization }\end{array}$ & $\begin{array}{l}\text { Traditional culture applied } \\
\text { to the costume design }\end{array}$ \\
\hline $\begin{array}{l}\text { Cultural knowledge } \\
\text { activities }\end{array}$ & $\begin{array}{l}\text { Cultural knowledge, economic activities, } \\
\text { cultural shopping, cultural services and } \\
\text { cultural knowledge and tourism together }\end{array}$ & $\begin{array}{l}\text { Combination of noble and } \\
\text { affordable }\end{array}$ \\
\hline
\end{tabular}

\section{Network era of fashion design representative concept}

Fashion design network has become a new concept of modern fashion design. Under the guidance of the network clothing design, many people put forward the "virtual costume design, ultra-dimensional visual clothing design, green clothing design, cultural connotation of clothing design" and other modern clothing design concept.

\subsection{Virtual clothing design}

Virtual clothing design is a virtual real simulation with computer electronics technology for fabric simulation. It is the costume designer and computer electronics technology and animation technology. The best combination of virtual clothing design is widely used in three-dimensional fashion design and garment industry, three-dimensional film, television, computer advertising and other special production areas. In the United States virtual, clothing design site has appeared a lot. On the one hand, 
they can use the network for online design. Customers and designers can design the clothing model for two-dimensional clothing film design after wearing a three-dimensional model Business. By selecting and setting the physical mechanical properties of the fabric parameters, gravity, wind, designers can talk to the clothing and the human body dynamics simulation and simulation according to the movement of the human body series. By observing the motion simulation and simulation of three-dimensional clothing, the designer can visually examine it in fashion design and fabric and pattern selection. If the design is not satisfied with the results, you can immediately in two or three dimensional space for the shape and material changes to improve its effect. From a certain extent, it can also show the fabric hanging feeling and mechanical properties. While customers see their wearing effect, then they can come to the perfect design and artistic satisfaction immediately after the purchase.

On the other hand, it is the virtual costume design. Currently according to the online sales of clothing, the United States online sales of clothing has been in the clothing sales accounted for a certain proportion. The reason is through the site, such as people can use the three-dimensional technology to simply upload their own body's necessary data, such as height, chest circumference, waist circumference, hip circumference, age, type of clothing selected, etc. After they enter the website, the website can calculate the customer's physical characteristics after trying to wear the customer selected style according to the body type classification method. Customers will be able to see their own clothing in the terminal wearing a dynamic effect, so you can choose the most suitable, most satisfied with the clothing. This online virtual costume design is also a combination of design and sales virtual and the most successful sales of today's website.

\subsection{Ultra-dimensional visual clothing design}

The so-called super-dimensional refers to the one-dimensional space line, two-dimensional space surface, three-dimensional space volume, four-bit space time, five-dimensional space ideas. Modern super-dimensional visual design is to people's psychology, human vision and human aesthetic. Human taste and many other factors of the product are based on the original five-dimensional design beyond the increase, ultra-dimensional design attention. The use of environmental psychology and ornamental psychology have gone beyond the spatial dimension of the relationship. In the past, we emphasized the role of space composition, but only many designers designed the space as a flat space composition. Bue we must ignore its environmental beauty and the overall beauty.

Super-dimensional design can develop and enrich the designer's visual design thinking. In the past, we only pay attention to the picture shape, color, composition of the narrow space. Now, we must psy attention to the concept of super-dimensional visual design with a higher creative spirit. Psychological, environmental science and technology are a comprehensive concern and co-ordinate the design. These can improve the overall development of space. In the network clothing design, the original costume design is only two-dimensional plane to three-dimensional three-dimensional transformation. It will appear flat cutting method of the proportion of cutting. They are completed with the shape of the human body and it is often a direct link. The current concept of network design in the ultra-dimensional visual design is to establish the concept of super-dimensional visual design and it is the use of the original five-dimensional space based on the improvement and beyond. Clothing in different spaces will have different spatial location, which includes Clothing design and art design of a combination of means such as: color, light, area, location, plane, three-dimensional, visual and spatial functions combined with the design. The design of network clothing not only attaches importance to the dressing effect of clothing and the theme of thinking, but also attach importance to the local physical environment. It can interrelate spatial morphology and other psychological factors. The creation of space visual environment is a comprehensive system of human, clothing and environment.

\subsection{Green clothing design}

Green clothing design is based on people in the industrial development of energy waste, environmental pollution, ecological damage awareness. Green design is to save and protect the environment as the main purpose of the design calendar and methods. From the perspective of art design, more from the return to the natural environment, the nature of the form; especially the 
introduction of color design to arouse people love nature, the protection of natural consciousness. Designers show the respect and attention to nature in various forms.

In the twenty-one real network era, this is due to the accelerated pace of modern life, people's spirit of high tension, so that people from the new understanding of the quiet pastoral life warmth. Friendship and elegant classical atmosphere bring warm comfort. Therefore, these are a reflection of the return to nature.

\subsection{Cultural connotation of clothing design}

"Twenty-first Century" is the century of culture and people have a more urgent demand for culture, which requires clothing designers in the innovation of different cultural means. People think that the network is modern and the national culture is postmodern, for the cultural connotation of clothing to inherit the national tradition. As the 2001 Shanghai APEC conference attracted Chinese fashion new fashion, clothing industry immediately blows the Chinese style. For the clothing business, the design is the pulse of the enterprise beating and the design will always serve the customers and the market. Only the network clothing design to bring customers to the design stage can achieve mutual interaction between customers and enterprises in order to achieve the true sense of the network Fashion Design. Network clothing design of the new concept of "virtual clothing design, ultra-dimensional visual clothing design, green clothing design, cultural connotation of clothing design" on the online design has a clear concept of clothing, because all the artistic design means of expression. The development of science and technology are in the development of artistic ideas under the guidance of the natural form.

\section{Summary}

With the continuous development of information network technology, people have become more and more familiar with the Internet. It is all over the world in every corner. In developed countries and regions, it has become an indispensable part of people's lives. It can be said that the Internet is in a new way of transmission of another revolution. For the fashion design of the Internet in a new way of transmission, it can change the traditional design concept and the results can affect the future of clothing design and clothing information release form.

\section{References}

[1] Cui Rongrong. Modern clothing design culture [M]. China Textile University Press, 2001.

[2] Tang Yu Bing. Costume design performance [M]. Higher Education Press, 2003.

[3] Liu Yuanfeng. Fashion Design [M]. Higher Education Press, 2006. 